\title{
Kearifan Lokal dan Aktifitas Filantropi Perantau Sulit Air Sepakat (SAS) dalam Menghadapi Revolusi Industri 4.0
}

\author{
Addiarrahman \\ UIN Sultan Thaha Saifuddin Jambi, Indonesia \\ addiarrabman@uinjambi.ac.id
}

\begin{abstract}
This article describes the practice of philanthropy of the diaspora of Sulit Air Sepakat (SAS) in facing the industrial revolution 4.0. Merantau as a form of local wisdom of the Minangkabau people based on Adat Bersendi Syara', Syara' Bersendi Kitabullah (ABS-SBK), forming Islamic philanthropic behavior that can keep up with the times. However, the management system applied is still traditional. After SAS was officially incorporated as a Perkumpulan, it was a strategic change in knitting the power of diaspora philanthropy. Through participatory action research, this article reveals the philanthropic activities of Sulit Air diasporas in the era of industrial revolution 4.0 is to establish SAS information systems, utilization of social media, and programs to improve the quality of human resources.
\end{abstract}

Keywords: Philanthropy, Perantau, Industrial Revolution 4.0,

\begin{abstract}
Abstrak
Artikel ini mendeskripsikan praktik filantropi kaum perantau Sulit Air Sepakat (SAS) dalam menghadapi revolusi industry 4.O. Merantau sebagai bentuk kearifan lokal masyarakat Minangkabau yang berlandaskan Adat Bersendi Syara', Syara' Bersendi Kitabullah (ABS-SBK), membentuk prilaku filantropi islami yang dapat mengikuti perkembangan zaman. Akan tetapi, sistem manajemen yang diterapkan masib bersifat tradisional. Setelah SAS secara resmi berbadan bukum perkumpulan, perubahan strategis dalam merajut kekuatan filantropi kaum perantau. Melalui riset partisipasi aktif (participatory action research), artikel ini mengungkap aktifitas filantropi kaum perantau Sulit Air pada era revolusi industri 4.0 adalah dengan membentuk sistem informasi SAS, pemanfaatan sosial media, dan program peningkatan kualitas SDM.
\end{abstract}

Kata Kunci: Filantropi, Perantau, Revolusi Industri 4.0

Permalink/DOI: http://dx.doi.org/10.18326/infsl3.v13i1.177-200 


\section{Pendahuluan}

Praktik filantropi telah lama menjadi instrumen peningkatan kesejahteraan masyarakat yang meliputi aspek-aspek penting, seperti: pendidikan, kesehatan, keagamaan, sosial dan lain sebagainya. Sebagai contoh, pendirian Oxford University diawali oleh semangat filantropis yang menurut Cizacka menerapkan model wakaf (Cizakca, 1998). Masjid, pesantren, rumah sakit, sekolah, yang ada di Indonesia, atau fasilitas umum lainnya yang ada di Indonesia, juga tidak terlepas dari instrumen filantropi (Latief, 2010).

Keberadaan lembaga filantropi, pada dasarnya digerakkan oleh banyaknya bukti-bukti empiris yang menunjukkan pentingnya pemberdayaan potensi filantropi. Muhammadiyah melalui lazismu telah menjadi best practice yang telah membuktikan keberhasilan dalam mengelola filantropi islam, seperti: zakat, wakaf, infaq, shadaqah dan lain sebagainya (Baidhawy, 2015)this study found that: first, Muhammadiyah, as a non-profit social-religious organization, admits its role as an agent of transformation vis-àvis the State. Lazismu is able to show its flexibility to adapt to new trends in philanthropy. Lazismu is also able to initiate breakthrough in management of Zakat, Infaq, and Sadaqah and move them beyond charity activities to productive and redistributive activities to promote social justice and equity. Second, Lazismu shows creativity and sophisticated programs exceeding the expectations of muzakki (alms payer. Keberhasilan tersebut, tidak terlepas dari kemampuan lazismu beradaptasi dengan format filantropi baru, melakukan trobosan dalam pengelolaan filantropi Islam yang tidak hanya berorientasi pada amal yang bersifat teologis. Namun, juga dimaksudkan untuk program-program kreatif dan inovatif dalam bidang pendidikan, kewirausahaan, pemberdayaan perempuan, dan lain sebagainya.

Pada dasarnya, potensi filantropi terbentuk karena ditopang oleh faktor agama, ekonomi, pendidikan, budaya atau kearifan lokal, komunitas ekonomi/sosial, letak geografis (Latief, 2013; Mohd Arshad, 2016) . Pada kasus filantropi kaum perantau, Irdam Huri menegaskan bahwa kearifan lokal masyarakat Minangkabau 
yang berlandaskan pada filosofi adaik basandi syara', syara' basandi kitabullah (ABS-SBK), sangat mempengaruhi praktik filantropi kaum perantau Sulit Air (Huri, 2006). Hal yang sama juga ditegaskan oleh Dede Rusdiana dan Zaim Saidi, setelah melakukan riset diaspora giving (Rusdiana \& Saidi, 2008). Tradisi baragiah ka kampuang, menjadi motivasi filantropi utama perantau Sulit Air (Addiarrahman, 2013).

Sebagaimana ditegaskan oleh Baidhawi, keberhasilan suatu lembaga filantropi terletak pada kemampunya dalam mengadopsi model baru dalam tata kelola dan pemberdayaan sumber daya filantropi. Dengan kata lain, absenya kreatifitas dan inovasi dalam memberdayakan kedermawanan masyarakat, dapat menghilangkan kepercayaan orang dalam menyalurkan dana sosialnya. Pada titik ini, Perkumpulan Sulit Air Sepakat (SAS) sebagai organisasi yang telah memiliki 97 cabang yang tersebar di seluruh Indonesia, dan luar negeri (Malaysia, Melbourne, Sydney), tentunya perlu melakukan perubahan dalam pengelolaan filantropi kaum perantau. Kecenderungan ini mulai tampak setelah organisasi ini terdaftar sebagai organisasi berbadan hukum perkumpulan.

\section{Metode Penelitian}

Penelitian ini merupakan bagian dari studi ekonomi Islam dengan menggunakan model model penelitian observasi terlibat (participatory action research/PAR). Sebagai alternatif dalam riset kualitatif, PAR adalah aktifitas mengumpulkan dan menganalisis data secara sistematis yang tujuannya untuk melakukan suatu tindakan dan perubahan (MacDonald, 2012). Peneliti dalam PAR tidak memposisikan masyarakat atau komunitas sebagai objek penelitian semata, sebagaimana terjadi dalam penelitian kuantitatif, melainkan sebagai subjek, sehingga ia tidak bebas nilai. Artinya, selain melakukan penelitian, dalam seorang peneliti dalam PAR juga melakukan "aksi" dan "partisipasi" transformatif sebanyak mungkin masyarakat atau komunitas tertentu.

Perspektif yang digunakan dalam riset ini adalah in world looking (McCutcheon, 1999) karena, peneliti merupakan bagian 
dari pengurus Dewan Pimpinan Pusat Perkumpulan Sulit Air Sepakat (SAS). Oleh sebab itu, peneliti bisa melakukan aksi partisipatoris suatu ide, konsep, dan program kerja yang bertujuan agar terwujudnya perubahan dalam tata kelola potensi filantropi kaum perantau Sulit Air Sepakat. Data yang penulis sajikan dalam artikel ini diperoleh dengan cara melakukan sharing (berbagi cerita) dengan pengurus dan sesepuh SAS, wawancara mendalam (in-depth interview) dan diskusi kelompok terarah (focus grup discussion).

\section{Nilai Filantropi Islam dalam Karifan Lokal Merantau}

Tsuyoshi Kato mengidentifikasi tiga karakter yang melekat pada masyarakat Minangkabau, yaitu: keyakinan yang kuat terhadap Islam, merantau, dan sistem matrilineal (Kato, 1980). Hubungan Islam dan adat tersimpul dalam pandangan hidup adat basandi syara', syara' basandi kitabullah (ABS-SBK). Simpulan ini lahir setelah melewati konflik dan ketegangan antara kaum agama dan kaum adat (Noer, 1985). Atas dasar filosofi tersebut, adat menjadi bentuk ideal perilaku masyarakat Minangkabau (Abdullah, 1966).

Kuatnya hubungan antara Islam dan adat mengindikasikan bahwa Islam dalam kearifan lokal Minangkabau, menjadi timbangan berlakunya nilai adat di tengah masyarakat. Di satu sisi, Islam menjadi inspirasi terhadap lahirnya adat, namun di sisi yang lain juga mengoreksi nilai adat yang bertentangan dengan pokok utama syariat Islam. Oleh sebab itu, kategorisasi adat pun ditentukan berdasarkan hirarki yang memposisikan Islam sebagai hirarki yang paling tinggi. Yaitu: 1) adat nan sabana adat, yaitu hukum Allah baik yang qauli maupun kauni;2) adat nan diadatkan atau adat yang telah diwariskan oleh nenek moyang masyarakat Minangkabau, namun tetapi menjadikan al-Quran dan al-Hadis sebagai ukurannya; 3) adat nan teradat, yaitu adat yang berlaku di daerah tertentu di wilayah Minangkabau; 4) adat istiadat, atau yang dibuat untuk merespon sesuatu (Navis, 1984). Jenis adat yang pertama dan kedua disebut juga dengan istilah adat nan babubu mati atau adat yang tidak boleh diubah. Sedangkan jenis adat yang ketiga dan keempat, adalah adat nan babubu sentak, yang bisa berubah sesuai dengan perubahan zaman. 
Merantau sebagai identitas budaya masyarakat Minangkabau, tidak terlepas dari nilai-nilai islami. Hal ini teridentifikasi dari tujuan merantau sebagaimana dapat dipahami dalam pepatah "merantau bujang dabulu, di rumah baguno balun" (merantau bujang dahulu, di rumah atau di kampung belum berguna untuk keluarga dan masyarakat). Sistem matrilineal yang dipegang oleh masyarakat Minangkabau menuntut kaum laki-laki harus bekerja keras agar dapat memberikan kemaslahatan yang seluas-luasnya. Tidak hanya untuk diri sendiri atau keluarga, tetapi juga untuk masyarakat umum. Hal ini tertuang dalam pepatah "anak dipangku kamanakan dibimbiang, urang kampuang dipatenggangkan, tenggang nagari jan binaso. (anak dipangku, kemenakan dibimbing, orang kampung dipertenggangkan, tenggang nagari jangan binasa).

Pepatah ini, baik dihafal maupun tidak menjadi inspirasi bagi perantau Minangkabau, khususnya Sulit Air, untuk membangun kampung halaman mereka. Tenggang nagari jan binaso, bukan sekedar menjaga nagari dari kemaksiatan dan kejahatan, namun melakukan pembangunan dalam segala lini kehidupan. Mulai dari ekonomi, sosial, seni, budaya, politik, hukum, hingga kehidupan beragama. Bagi masyarakat Sulit Air, kepedulian terhadap kampung halaman, sanak famili terungkap dalam pepatah berikut:

Apo gunonyo kabau Batali

(Apa gunanya kerbau bertali)

Usah dipawik di pematang (Jangan diikat di pematang)

Pawikkan sajo di tangah padang (Ikatkan saja di tengah padang)

Apo gunonya badan mancari (Apa gunanya badan mencari)

Iyo pamaga sawah jo ladang (Untuk memagar sawah dan ladang)

Nak mambela sanak kanduang (Untuk membela saudara kandung)

Bekerja keras di rantau orang. Siang malam pagi dan petang. Tak lain adalah bertujuan untuk pamaga (memelihara) sawah dan ladang (nagari, kampung halaman). Banyak cara yang dilakukan. Mulai dari memberikan bantuang uang buat sanak famili, hingga membangun berbagai fasilitas yang dibutuhkan oleh masyarakat. Misal, pembangunan surau, masjid, jalan, sekolah, 
dan lain sebagainya. Semangat ini, tidak terlepas dari pemahaman masyarakat Sulit Air terhadap anjuran memberikan sedekah kepada karib kerabat sebagaimana disebutkan dalam al-Quran surat albaqarah ayat 177 .

\section{Kearifan Lokal di Era Revolusi Industri 4.0}

Revolusi Industri 4.0 memberikan banyak kemudahan bagi manusia. Akan tetapi, ia juga bisa menimbulkan banyak persoalan terhadap masa depan peradaban manusia. Sistem kapitalismeneoliberalisme yang melatari perkembangan revolusi industry 4.0 mengancam terwujudnya agenda pembangunan berkelanjutan (sustainable development goals). Perangkat nilai individualismeutilitarinisme yang menjadi sistem nilai kapitalisme-neoliberalisme merupakan akar persoalannya.

Oleh sebab itu, dalam khazanah pembangunan pasca modernis, sebagaimana dijelaskan oleh M. Dawam Rahardjo, sangat memerlukan perangkat nilai kearifan lokal (M. D. Rahardjo, 2012). Riset membuktikan bahwa kearifan lokal menjadi piranti untuk mewujudkan ketahanan masyarakat (Patriadi, Bakar, \& Hamat, 2015), pengembangan ekonomi mikro (Rankin, 2002), manajemen air bersih (David \& Ploeger, 2014), pariwisata (Vitasurya, 2016), dan isu lainnya. Temuan-temuan empiris tersebut menjadi argumen akademis bahwa nilai Islam dalam kearifan lokal aktifitas filantropi perantau Sulit Air, bisa menjadi media transformasi sosial untuk meningkatkan kesejahteraan masyarakat, khususnya perantau dan warga Sulit Air.

Pada riset sebelumnya, penulis menyimpulkan bahwa tradisi baragiah ka kampuang merupakan modal sosial perantau Sulit Air yang bisa menjadi sistem nilai dalam pembangunan nagari (Addiarrahman, 2013). Pada titik ini, diskusi yang diperlukan bukanlah berkaitan dengan sistem nilai. Sebaliknya adalah proses merumuskan pendekatan atau model yang dapat diterapkan untuk memberdayakan potensi filantropi kaum perantau Sulit Air. 


\section{Sejarah Singkat Perkumpulan Sulit Air Sepakat (SAS)}

Sebagai sebuah organisasi, Sulit Air Sepakat (SAS) dibentuk berdasarkan konferensi pembentukan SAS yang diselenggarakan 3-5 Juli 1970 di Ciloto, Bogor. Sebelum tanggal tersebut, daerahdaerah tertentu telah mulai menggunakan nama "Sulit Air Sepakat" sebagai wadah perkumpulan perantau Sulit Air. Meskipun, namanama lain banyak bermunculan, namun terbentuknya SAS menjadi kesepakatan bersama bahwa satu-satu organisasi perantau Sulit Air adalah SAS. Pada Tahun 2007 Sulir Air Sepakat (SAS) resmi berbadan Hukum yang telah dicatat dalam Surat Keputusan Menteri Hukum dan Hak Asasi Manusia Republik Indonesia tertanggal 08 Maret 2007, Nomor : C-19.ht.01.03.TH.2007.

Kapan dan siapa yang pertama kali menggunakan nama SAS masih menjadi tanda tanya. Ditemukannya semacam prasasti yang bertuliskan "SAS 1912" di Taman Pemakaman perantau Sulit Air di Mato Aie, Padang menimbulkan kontroversi tentang kapan berdirinya SAS. Berdasarkan prasasti tersebut, Hamdullah Salim berkeyakinan bahwa SAS telah ada sejak tahun 1912 (Salim, 2017). Ia juga mengkaitkan eksistensi SAS dengan kedudukan Mahyuddin Dt. Sutan Maharadja atau dikenal Dt. Bangkik sebagai the father of Malay journalism yang banyak menggerakkan masyarakat Sulit Air, khususnya perempuan dengan mendirikan sekolah menjahit dan juga menjadi jurnalis.

Namun, Taufik Abdullah yang melakukan kajian mendalam terhadap peran Mahyudin Dt. Sutan Maharadja dalam modernisasi Minangkabau, sama sekali tidak mencatat keterlibatan Dt. Bangkik dalam pembentukan organisasi SAS (Abdullah, 1972). Sebaliknya, sebagai generasi pertama Minangkabau yang mengenyam pendidikan barat (western educated), Dt. Sutan Mahardja dan anaknya Zubaedah Ratna Juita bersama Rohana Kudus dari Koto Gadang, menjadi pelopor pers di Minangkabau dan pada tahun 1912 mendirikan Soenting Melajoe sebagai surat kabar perempuan pertama di sumatera. Terlepas dari itu, terdapat kesepakatan bahwa perkumpulan perantau Sulit Air, memang telah ada sejak tahun 1912 bahkan jauh sebelumnya. Setelah berhasil mendirikan sekolah untuk laki-laki pada tahun 1907, Dt. Sutan Mahardja tahun 
1909 mendirikan sekolah menjahit pertama bagi perempuan yang diberi nama "the padangsche weefschool." Lima orang penjahit berpengalaman dari Sulit Air, ia undang sebagai guru pada sekolah tersebut. Selanjutnya, pada tahun 1912, tulis Taufik Abdullah, "instead of sending teachers, Sulit Air sent several students to study at the school (Abdullah, 1972)." Keberadaan sekolah ini juga didukung dengan adanya pemeran dagang (the trade fair) yang ia bentuk pada tahun 1908 untuk memasarkan produk jahitan, dan karena banyaknya kelompok pedagang yang terlibat, pemeran tersebut menjadi agenda tahunan.

Setelah Dt. Sutan Maharadja wafat pada tahun 28 Juni 1921, Zainal Abidin Ahmad dan Joesoef Ahmad menjadi tokoh yang menggerakkan kegiatan sosial perantau Sulit Air. Sebelum kedua tokoh ini lahir, Mr. Mohammad Djamin Dt. Sutan Mahardja Besar, merupakan cendikiawan Sulit Air yang pertama kali menempuh pendidikan di Universitas Leiden, Belanda. keberhasilan dia sebagai sarjana hukum, agaknya ikut mempengaruhi motivasi merantau generasi muda Sulit Air pasca kemerdekaan untuk melanjutkan kuliah di Perguruan Tinggi, yang banyak di bidang hukum. Berdasarkan usul H. Sulaiman al-Khalidi, Mr. Mohammad Djamin bersama Rasyad Dt. Temanggung mendirikan Masjid Raya Sulit Air pada tahun 1911. Belakangan, Mr. Mohammad Djamin menjadi Gubernur Jawa Barat pertama.

Sebelum berusia 20 tahun, Zainal Abidin Ahmad telah menjadi ketua Permusyawaratan Islam Sulit Air (PISA) yang kemudian diubah menjadi Permusyawaratan Islam (PI). Melalui perannya ini, Zainal membentuk Ruang Pendidikan Islam (RPI) dan Pergerakan Ekonomi Rakyat (PER) pada tahun 1943 (Soebagio I.N, 1985). Lebih jauh, kedua tokoh ini juga menjadi penggerak terselenggaranya Konferensi Tradisionil yang membahas pembangunan Nagari Sulit Air di berbagai bidang, seperti pendidikan, ekonomi, perkebunan, pertambangan, adat, dan lainnya. Melalui majalah Pandji Islam, keduanya juga ikut menggaungkan nama perantau Sulit Air di Indonesia, bahkan sampai ke luar negeri.

Pasca kemerdekaan, geliat berorganisasi perantau Sulit Air semakin meningkat. Pada tahun 2 Juli 1951, para pelajar dan 
pemuda Sulit Air membentuk Ikatan Pemuda Pelajar Sulit Air (IPPSA). Aktifitas pelajar dan pemuda Sulit Air, baik di rantau maupun di kampung halaman, semakin mempengaruhi perubahan sosial masyarakat Sulit Air.

Pada hari jumat, 13 Januari 1963 di Jakarta, dihadapan notaris Raden Mas Soerojo, empat orang tokoh Sulit Air, yaitu: Mohammad Joesoef Ahmad, Iljas Abdul Latief Dt. Nan Sati, Amir Shambazy, dan Amir Aslan Tamin, dengan modal Rp. 16.800,membentuk Jajasan Pembangunan Sulit Air (JAPSA). Pada pasal 3 AD/ART YAPSA, disebutkan bahwa "yayasan ini bertujuan untuk membangun negeri dan warganegeri Sulit Air dalam segala bidang terutama dalam bidang agama, pendidikan, sosial, perekonomian, kebudayaan, dan ilmu pengetahuan." Djamaluddin Adenegoro sebagai ketua umum YAPSA, menegaskan "Gerakkanlah masjarakat desa, masjarakat jang besar, jang tersebar di selurub Indonesia, menurut kesanggupan masing-masing pentjinta desa masingmasing, yang achirnja mendapat pula mempengarubi dengan konkrit pembentukan Nationbuilding Indonesia Baru"(Adinegoro, 1963). Akan tetapi, aktifitas YAPSA hilang karena situasi politik yang memanas karena gerakan komunis.

Dinamika dan gerakan sosial perantau Sulit Air pada dasarnya sangat kompleks. Hamdullah Salim dalam bukunya Sejarah $S A S$, cukup detil dalam menuliskan pergulatan perantau Sulit Air dalam membentuk perkumpulan Sulit Air Sepakat (SAS). Sejak dibentuk pada tahun 1970, SAS secara perlahan melakukan perubahan demi perubahan, di balik ketegangan dan konflik yang mewarnainya. Namun, terjadi perubahan yang cukup penting setelah SAS secara sah berbadan hukum "perkumpulan". Dari segi kepemimpinan, Perkumpulan SAS pernah dipimpin oleh tokoh dengan latar belakang yang beragam: ulama, pengusaha, notaris, TNI, dan lainnya. 
Tabel 1. Profil Ketua Umum DPP SAS 1970-2019

\begin{tabular}{|c|c|c|c|c|c|}
\hline No & Nama & T.T.L & Suku & Pekerjaan & Periode \\
\hline 1 & $\begin{array}{l}\text { H. Syamsul } \\
\text { Bahri Nur }\end{array}$ & & $\begin{array}{l}\text { Limo Panjang } \\
\text { Topi Ayie Di } \\
\text { bawah Payung } \\
\text { Dt. Tamandaro }\end{array}$ & Ulama & $1969-1971$ \\
\hline 2 & $\begin{array}{l}\text { H. Rozali } \\
\text { Usman, SH }\end{array}$ & & Limo Singkek & $\begin{array}{l}\text { Penerbit } \\
\text { Remaja } \\
\text { Rosdakarya }\end{array}$ & $\begin{array}{c}1972-1973 \\
\& 1981\end{array}$ \\
\hline 3 & $\begin{array}{l}\text { H. Amir } \\
\text { Shambazy }\end{array}$ & $\begin{array}{l}\text { Sulit } \\
\text { Air, } 15 \\
\text { Oktober } \\
1928\end{array}$ & $\begin{array}{l}\text { Limo Panjang } \\
\text { Topi Ayie di } \\
\text { Bawah Payung } \\
\text { Dt. Tamandaro }\end{array}$ & $\begin{array}{l}\text { Pengusaha } \\
\text { Bidang } \\
\text { Farmasi }\end{array}$ & $1977-1978$ \\
\hline 4 & $\begin{array}{l}\text { Letkol. } \\
\text { H. Armon } \\
\text { Syamsuddin }\end{array}$ & & $\begin{array}{l}\text { Simabu Bodi di } \\
\text { Bawah Payung } \\
\text { Dt. Panghulu } \\
\text { Sutan }\end{array}$ & $\begin{array}{l}\text { Purnawirawan } \\
\text { TNI }\end{array}$ & $1979-1981$ \\
\hline 5 & $\begin{array}{l}\text { H. } \\
\text { Fachruddin } \\
\text { Panuh, B.A }\end{array}$ & & $\begin{array}{l}\text { Simabu Ilie di } \\
\text { Bawah Payung } \\
\text { Dt. Pono } \\
\text { Marajo }\end{array}$ & Notaris & $1982-1984$ \\
\hline 6 & H. Nur Aksar & & $\begin{array}{l}\text { Limo Panjang } \\
\text { Topi Ayie di } \\
\text { Bawah Payung } \\
\text { Dt. Tamandaro }\end{array}$ & Kontraktor & 1984-1986 \\
\hline 7 & $\begin{array}{l}\text { H. Zulherfin } \\
\text { Zubir }\end{array}$ & $\begin{array}{l}\text { Bandung, } \\
21 \text { April } \\
1952\end{array}$ & $\begin{array}{l}\text { Limo Panjang } \\
\text { Topi Ayie di } \\
\text { Bawah Payung } \\
\text { Dt. Rajo } \\
\text { Mangkuto }\end{array}$ & $\begin{array}{l}\text { Pengusaha } \\
\text { Bidang } \\
\text { Percetakan }\end{array}$ & 1998-2010 \\
\hline 8 & $\begin{array}{l}\text { Drs. H. } \\
\text { Zarkasyi } \\
\text { Nurdin, S.H }\end{array}$ & $\begin{array}{l}\text { Solok, } \\
19 \text { April } \\
1954\end{array}$ & $\begin{array}{l}\text { Limo Singkek } \\
\text { Sojik di Bawah } \\
\text { Payung Dt. } \\
\text { Podo Gomuk }\end{array}$ & Notaris & 2010-2017 \\
\hline
\end{tabular}




\begin{tabular}{cllll} 
Samsuddin & Siak, 18 & Limo Panjang & Owner & 2017-2021 \\
& Mei 1965 & Rumah Godang & Samrucci \\
& 20 di bawah & Grup \\
& Payuang Dt. & \\
& Tamaruhun & \\
\hline
\end{tabular}

\section{Sumber: Profil Sulit Air Sepaka}

\section{Aktifitas Filantropi Perantau Sulit Air}

Aktifitas filantropi perantau Sulit Air dapat dibagi ke dalam tiga fase, yaitu: sebelum kemerdekaan, pasca kemerdekaan, dan pasca reformasi yang terbagi lagi menjadi dua, yaitu: sebelum dan sesudah berbadan hukum perkumpulan. Sub bagian ini membahas secara umum aktifitas filantropi perantau Sulit Air pada tiap-tiap fase tersebut. Namun, sebagaimana hasil penelitian saya sebelumnya, aktifitas filantropi perantau Sulit Air dipengaruhi oleh kearifan lokal masyarakat Sulit Air yang berlandaskan pada Adat Basandi Syara, Syara Basandi Kitabullah. Kearifan lokal tersebut membentuk modal sosial (social capital) baragiah ka kampuang (Addiarrahman, 2013).

\section{Sebelum Kemerdekaan}

Sekolah menjahit (thepadangsche weefschool)yang didirakan oleh Mahyuddin Dt. Sutan Maharadja dapat dikatakan sebagai contoh aktifitas filantropi pertama yang dilakukan oleh perantau Sulit Air. Sekolah ini tidak hanya bermanfaat bagi masyarakat Sulit Air, tetapi juga masyarakat Minangkabau pada umumnya. Perhatian terhadap dunia pendidikan, agaknya menjadi fokus utama para perantau Sulit Air. Berdirinya Pendidikan Sekolah Agama (PSA) pada tahun 1925, menjadi contoh terbaik aktifitas filantropi perantau Sulit Air di bidang pendidikan. Elizabeth E. Graves menegaskan bahwa Sulit Air termasuk nagari di Minangkabau yang sangat kuat perhatiannya terhadap dunia pendidikan, di samping Koto Gadang (Graves, 2007). 
Pendirian PSA Sulit Air dipengaruhi oleh Perguruan Sumatera Thawalib yang pada saat itu menjadi episentrum pendidikan modern di Sumatera Barat, di samping sekolah lain yang lebih awal: Diniyah School Padang Panjang yang didirikan oleh Zainuddin Labay El-Yunusi, dan Diniyah Puteri Padang Panjang yang dibangun oleh Rahmah El-Yunusiah.

Labai Muhammad Yasin adalah guru agama pertama kali berkeinginan mendirikan sekolah agama, sebagaimana yang diterapkan oleh Sekolah Diniyah. Pada tahun 1923, ide ini kemudian ia sampaikan kepada dua orang temannya, Jamin Yahya dan Jamin Hamzah. Pada tahun 1925, setelah melewati proses musyawarah yang melibatkan seluruh tokoh masyarakat, kelas pertama PSA Sulit Air mulai dibuka di Surau Tabing. Kemudian, selama dua tahun, sekolah PSA berpindah-pindah dari surau ke surau. Dari surau tabing pindah ke surau lubuk singgodang, kemudian setelah enam bulan, pindah lagi ke surau muruk. Pada tahun 1927, PSA telah memiliki ruang kelas di Gando, Sulit Air. Pembangunan gedung PSA ini, melibatkan seluruh masyarakat Sulit Air dengan mengangkat batu dari sungai, dan partisipasi perantau Sulit Air dari berbagai daerah (Zainal Abidin Ahmad, dkk, 1978).

Selain pendirian sekolah, aktifitas filantropi perantau Sulit Air juga disalurkan dalam bentuk bantuan pendidikan. Kahrudin Yunus adalah 'anak emas' nagari Sulit Air yang pertama kali memperoleh bantuan pendidikan guna melanjutkan pendidikannya di Egyptian University, Mesir. Pada tahun 1939, Kahrudin berangkat menuju Mesir dan tercatat sebagai mahasiswa Fakultas Perdagangan. Pada kampus yang sama, ia menyelesaikan studinya di bidang Politik Ekonomi pada tahun 1947. Pada tahun 1949, ia tercatat sebagai mahasiswa program doktor di Columbia University. Namun, kuliah ini tidak terselesaikan dan berkat beasiswa pemerintah Republik Indonsia, ia memperoleh gelar Ph.D dari American University pada tahun 1954. Kuntowijoyo dan M. Dawam Rahardjo menegaskan bahwa Kahrudin Yunus adalah ekonom Islam pertama yang menulis buku Sistem Ekonomi Islam secara sistematis (Kuntowijoyo, 1991; D. Rahardjo, 2015). 


\section{Pasca Kemerdekaan}

Pasca kemerdekaan, gelombang merantau masyarakat Sulit Air semakin meningkat. Seturut dengan itu, geliat berorganisasi juga semakin tinggi. Tingginya arus merantau ke Yogyakarta dengan tujuan kuliah, mendorong perantau Sulit Air mendirikan Wisma Gunung Merah. Ide ini kemudian diawali oleh mahasiswa Sulit Air di Yogyakarta, secara bersama-sama menyewa rumah sebagai tempat tinggal. Kemudian, rumah yang berada di jalan Urip Sumoharjo No. 51 Yogyakarta dibeli. Pembelian rumah tersebut bisa terwujudkan berkat sumbangan perantau Sulit Air yang dikumpulkan dari berbagai daerah, seperti: Yogyakarta, Solo, Semarang, Pekanbaru, Curup, Kerinci, Muara Dua, Palembang, DKI, Lampung, dan lainnya.

Pada tahun 1969, warga Sulit Air di Teluk Betung, Lampung berhasil mendirikan masjid yang diberi nama Darul Muslihin. Selain sebagai tempat ibadah, masjid ini juga dimanfaatkan sebagai tempat berkumpul segenap warga Sulit Air yang ada di Teluk Betung. Penting dicatat, aktifitas filantropi perantau Sulit Air tidak hanya terfokus untuk masyarakat di Nagari Sulit Air, tetapi juga di seluruh daerah perantauan. Semangat pembangunan gedung serba guna, masjid atau mushalla, terus berlanjut dan hingga saat ini, di tiap cabang, SAS telah memiliki asset berupa tanah dan gedung.

Pada tahun 1975, perantau Sulit Air melakukan renovasi Masjid Raya Sulit Air secara total, sehingga pada saat itu digadanggadangkan sebagai masjid termegah di Sumatera Barat. Sedangkan pada tahun 1978, melalui sponsor utama keluarga Rosma Rais yang merupakan alumni PSA, serta didukung oleh perantau lainnya, telah dilakukan pembangunan gedung sekolah PSA Sulit Air sebanyak 12 kelas di gedung dua lantai.

Periode 1986-1998 di bawah kepemimpinan Rainal Rais Dt. Rajo Sati Nan Mulie, merumuskan program-program strategis, misalnya: pendirian Bank Perkereditan Rakyat (BPR) Surya Katialo yang modalnya dikumpulkan dari hasil penjualan saham kepada masyarakat Sulit Air (D'Kincai, 2003). Keberadaan BPR ini pada mulanya sangat membantuk laju perekonomian masyarakat Sulit 
Air di kampung halaman. Akan tetapi, karena faktor manajerial dan likuiditas, BPR Surya Katialo pada akhirnya ditutup.

\section{Pasca Reformasi}

Setelah reformasi, aktifitas filantropi perantau Sulit Air sedikit melemah sebagai dampak krisis moneter. Tidak banyak perubahan aktifitas filantropi yang dilakukan oleh perantau Sulit Air. Akan tetapi, bantuan uang yang dikirim melalui kantor pos, tetap dilakukan, sehingga Sulit Air dikenal sebagai "Kota Wesel". Di samping itu, penyaluran beasiswa kepada siswa berprestasi dan kurang mampu terus dilakukan oleh pribadi maupun yayasan yang dibentuk oleh perantau Sulit Air, seperti: Yayasan Gunung Merah, Yayasan Haji, Yayasan SAS Sydney, dan lainnya.

Geliat filantropi kembali meningkat setelah SAS di bawah kepemimpinan Zulherfin Zubir, mendirikan gedung serba guna SAS di bilangan Tebet. SAS semakin dikenal sebagai organisasi perantau Minangkabau terbesar. Ahmad Syafii Maarif dalam otobiografinya menulis bahwa Sulit Air Sepakat adalah contoh tersukses organisasi perantau Minangkabau (Maarif, 2009). Kepada penulis, Zulherfin Zubir menegaskan bahwa "sama sekali tidak ada penyesalan. apa yang saya lakukan semata ikhlas sebagai wujud rasa cinta dan pengabdian saya kepada Sulit Air. Cukuplah Allah mencatatnya sebagai bekal bagi saya di akhirat nanti."

Pada tahun 2007, Zulherfin berhasil mendaftarkan SAS sebagai organisasi berbadan hukum "perkumpulan". Sejak itu, agenda legalisasi seluruh asset SAS menjadi milik "Perkumpulan SAS" mulai dilakukan. Tujuannya adalah agar tidak terjadi konflik kepentingan di masa akan datang. Usaha ini berhasil dilakukan tiga bulan setelah Samsuddin diamanahkan menjadi Ketua Umum DPP SAS. Samsuddin langsung bergerak aktif melakukan proses balik nama asset DPP SAS di Jalan Sahardjo No. 115BX. Awalnya, banyak pihak yang meragukan kemampuan DPP melakukan hal itu karena biaya yang diperlukan terbilang cukup besar. Jika berpatokan pada nilai NJOP, DPP SAS harus menyiapkan dana + Rp. 970.000.000. Namun, dalam proses balik nama, dengan berbagai upaya yang 
telah dilakukan, proses balik nama tersebut bisa terwujud dengan hanya menghabiskan biaya Rp. 265.000.000,- Terhitung sejak tanggal 27 Desember 2017 dengan Nomor Sertifikat Hak Guna Bangunan: 00702/Manggarai Selatan telah resmi menjadi milik Perkumpulan SAS. Oleh sebab itu, DPP SAS telah menghimbau agar seluruh cabang melakukan hal yang sama melalui Surat Edaran Nomor SE.11/DPP SAS/XII/2017 tertanggal 08 Desember 2017.

Perubahan tata kelola filantropi perantau Sulit Air mulai dilakukan Zarkasyi Nurdin dengan membentuk database warga berbasis aplikasi. Program strategis ini disempurnakan dengan pengembangan Sistem Informasi SAS (Sinfo-SAS) berbasis website dengan alamat url: www.sas.or.id. Secara umum, SinfoSAS menyediakan informasi berkaitan dengan aktifitas warga SAS di setiap cabang, informasi beasiswa terpadu SAS, online library, database warga SAS, dan saat ini sedang dikembangkan Lazis-SAS yang tujuannya adalah mencontoh keberhasilan Lazismu dalam mengelola filantropi Islam masyarakat Indonesia (Sekjen DPP SAS, 2019). Pada bidang pendidikan, perantau Sulit Air yang tergabung dalam Dewan Dakwah Risalah, juga berhasil mendirikan Pondok Pesantren Modern Gontor 11 di Ompang, Talago Laweh, Sulit Air pada tahun 2008 .

\section{Filantropi Kaum Perantau pada Era 4.0}

Praktik aktifitas filantropi perantau Sulit Air sebagaimana dideskripsikan pada bagian sebelumnya, belumlah menjelaskannya secara rinci. Akan tetapi, gambaran umum tersebut cukup menggambarkan bagaimana kearifan lokal masyarakat Sulit Air telah membentuk gerakan filantropi yang sangat potensial untuk mewujudkan kesejahteraan masyarakat ("Kisah Sulit Air dan Orang orang Kaya," 2016). Akan tetapi, perkembangan teknologi informasi yang sangat pesat menyisahkan persoalan bagaimana aktifitas filantropi perantau Sulit Air di era revolusi industri 4.0. Secara sederhana, revolusi industri 4.0 dimulai sejak adanya robot pintar, big data, artificial intelligent, dan perkembangan neuroteknologi. Digitalisasi segala sistem menjadi konsekuensi kehadiran sistem supercomputer tersebut. 
Menyikapi kondisi tersebut, SAS melakukan adaptasi dalam menjaring potensi filantropi perantau. Adanya media sosial, seperti: WhatApps, Facebook, memberikan kemudahan SAS melaksanakan program filantropi. Pada grup-grup Whatsapps perantau Sulit Air, pengurus SAS dengan mudah mengumpulkan sumbangan untuk kepentingan pembangunan gedung serba guna, mushalla, bantuan sosial tanggap bencana, dan lain sebagainya. Sebagai contoh, pada saat terjadinya musibah gempa di Lombok, Perkumpulan SAS menyalurkan uang sebanyak Rp. 18.850.000,- dan $500 \mathrm{~kg}$ rendang siap saji. Sedangkan pada musibah gempa dan tsunami Donggala, SAS juga ikut berdonasi uang sejumlah Rp. 31.200.000,-. Secara keseluruhan, selama periode kepemimpinan Samsuddin, dompet SAS Peduli yang telah disalurkan untuk warga SAS dan masyarakat Indonesia yang tertimpa musibah adalah \pm Rp. 270.990.000,-

Untuk meningkatkan tata kelola filantropi perantau Sulit Air, saat ini, pengurus Dewan Pimpinan Pusat (DPP SAS), telah membuat database warga SAS yang terintegrasi dengan aplikasi Lazis-SAS dan hingga kini masih dilakukan proses input data oleh masing-masing pengurus cabang. Langkah ini, menurut Samsuddin merupakan "upaya kita mengejar ketertinggalan memanfaatkan teknologi informasi yang setiap hari perkembangannya semakin canggih.” Lebih lanjut, Samsuddin menjelaskan:

"Kalau keinginan untuk membangun nagari, warga SAS tidak perlu dipertanyakan. Tingginya rasa cinta mereka terhadap kampung, membuat mereka rela berkorban. Akan tetapi, saya melihat ada yang keliru dari cara kita selama ini mengekspresikan rasa cinta. Program-program yang dilakukan seringkali tidak terukur dan hanya dipicu oleh faktor emosi. Dampaknya, apa yang dilakukan tidak berkelanjutan. Awakko banyak emosi sajo, sehinggo apo yang dilakukan tidak terukur, dan kalau pun terukur seringkali belum jadi kebutuhan." (Samsuddin, 2019)

DPP SAS selalu berkomitmen melaksanakan programprogram yang manfaatnya dapat dirasakan lansung oleh masyarakat Sulit Air baik di rantau maupun di kampung halaman. Dalam proses implementasi suatu program kerja, DPP SAS selalu 
mengedepankan skala prioritas dan prinsip efektif dan efisien. Oleh sebab itu, program-program yang berdasarkan hasil kajian DPP SAS belum terlalu urgen, maka akan ditangguhkan terlebih dahulu. Atau karena dengan memperhatikan perubahan yang ada, DPP SAS melakukan perubahan terhadap rencana semula. Misalnya, program SAS Peduli pada mulanya hanyalah aksi spontanitas dan tidak termasuk dalam program DPP SAS. Namun, program SAS Peduli justeru menjadi program unggulan dan strategis untuk menunjukkan kepedulian sosial masyarakat Sulit Air terhadap segala bentuk musibah dan bencana yang dialami; baik oleh warga Sulit Air maupun masyarakat Indonesia pada umumnya. Hal ini sekaligus semakin mengukuhkan Perkumpulan SAS sebagai organisasi sosial yang memiliki kekuatan filantropis.
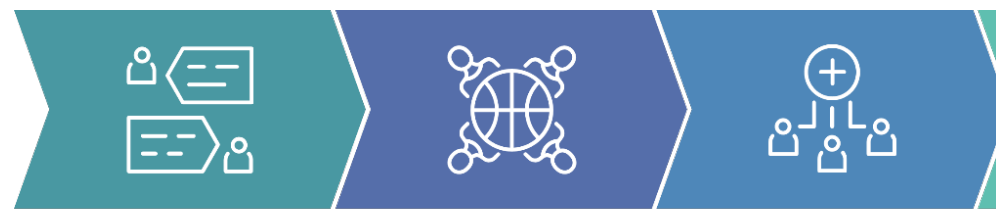

\section{Program Kerja}

Diskusi Terpadu

Rencana Aksi

Melakukan diskusi terpadu terhadap program yang direncanakan

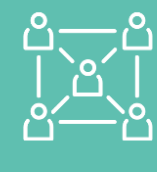

Implementasi \& Koordinasi

Mengimplementasikan

program kerja dengan tetap melakukan keoordinasi antar

\section{Gambar 1. Proses Implementasi Program Kerja}

Kurun waktu 2017-2019, DPP SAS boleh dikatakan tidak mendapatkan kendala yang bersifat prinsip dalam mengimplementasikan program kerja. Hambatan kecil terjadi disebabkan oleh faktor pengunduran diri pengurus dan kematian yang menimpa pengurus DPP SAS. Di samping itu, meskipun jarak kediaman masing-masing pengurus tersebar di berbagai daerah, keberadaan media sosial (WhatsApp) cukup membantu DPP SAS dalam melakukan komunikasi dan koordinasi lintas bidang.

Konflik dan dinamika organisasi merupakan fenomena yang wajar, sehingga DPP SAS selalu mengedepankan prinsip kekeluargaan dan silaturahim dalam menyelesaikan suatu 
masalah yang berkaitan dengan miscommunication atau hal lain yang bersifat non-organisatoris. Adapun masalah yang berkaitan dengan struktur organisasi, DPP SAS tetap berpedoman pada $\mathrm{AD} /$ ART dalam mengambil keputusan atau sikap terhadap suatu isu. Tentunya terlebih dahulu mengumpulan informasi dari sumber utama dan menganalisisnya secara mendalam. Sebagai contoh, masalah pembentukan cabang yang sempat menjadi "headlines" di WAG SAS.

Berdasarkan pelaksanaan program kerja selama 20172019, DPP SAS berikut penulis sajikan analisis SWOT bagaimana kesiapan perkumpulan SAS dalam mengelola potensi rantau untuk menghadapi revolusi industry 4.0.

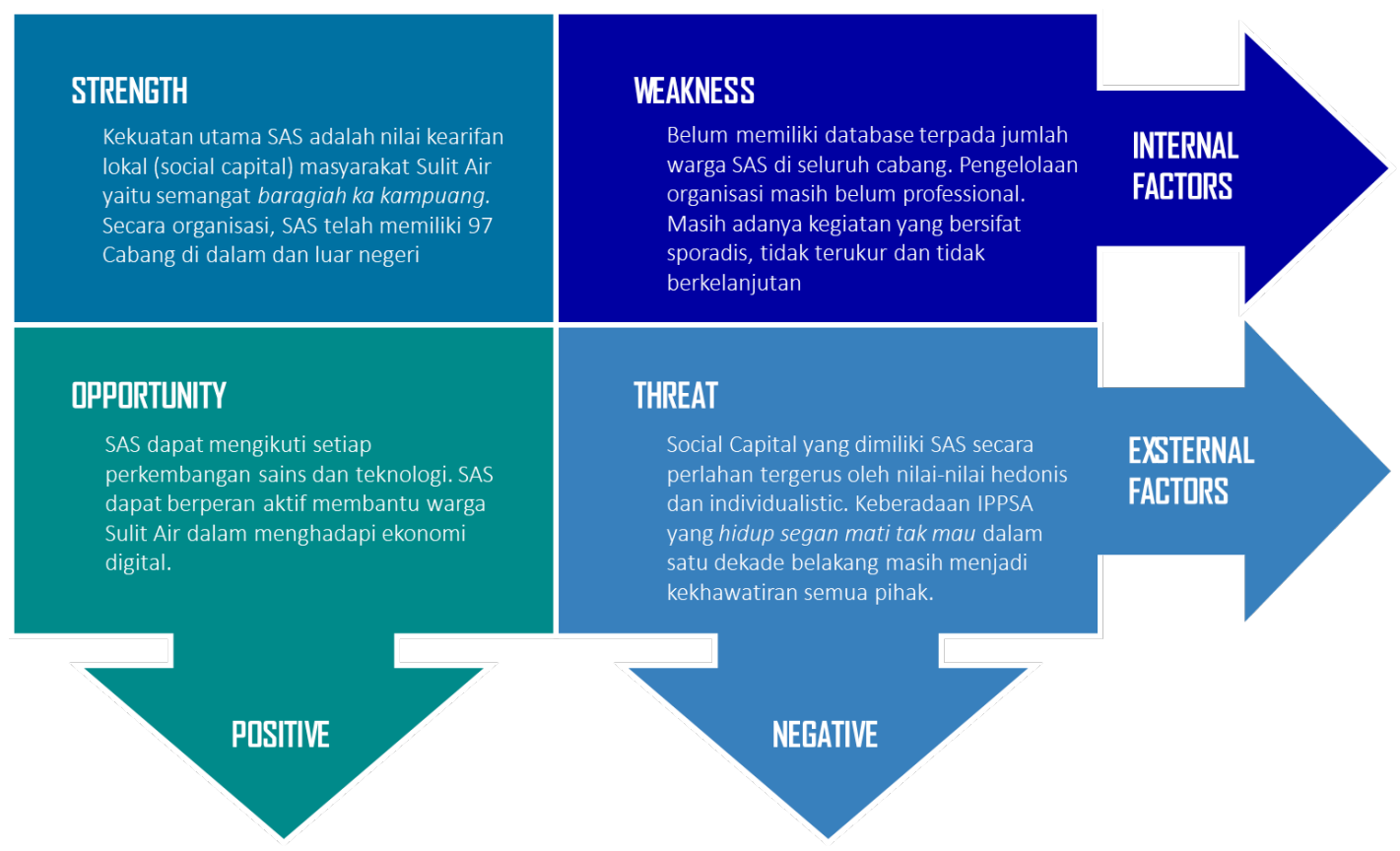

\section{Gambar 2. SWOT Analisis SAS dalam menghadapi Revolusi Industri 4.0}

Pada gambar di atas, akumulasi kelemahan dan ancaman SAS dalam menghadapi revolusi industri 4.0 berkaitan erat dengan tidak tersedianya database dan pada saat yang sama, social capital yang bersumber dari kearifan lokal Minangkabu terancam 
tergerus oleh nilai-nilai hedonis dan individualistik. Berkaitan yang pertama, data merupakan pra syarat kesiapan dalam menghadapi revolusi industri 4.0. Oleh sebab itu, pengembangan sistem informasi (Sinfo) SAS adalah solusi yang tepat yang harus terus dikembangkan secara berkelanjutan. Tidak hanya berhenti pada proses pengumpulan data, program ini diproyeksikan dapat membantu DPP SAS maupun DPC SAS di seluruh daerah dalam merumuskan program strategis dalam peningkatan kesejahteraan perantau Sulit Air.

Berkaitan dengan pembinaan dan penguatan nilai kearifan lokal Minangkabau pada generasi muda, perkumpulan SAS melakukan program pendidikan karakter berbasis kearifan lokal. Misalnya, seminar adat, program pekan budaya pada saat acara pulang basamo (mudik lebaran). Meskipun belum mencapai target yang diharapkan, kegiatan ini cukup membantu membentuk kesadaran budaya generasi muda perantau Sulit Air. Kesulitan yang dihadapi adalah karena generasi IPPSA dapat dibagi menjadi dua, yaitu: mereka yang lahir dan besar di rantau namun orang tuanya berasal dari Sulit Air; atau mereka yang lahir dan besar di Sulit Air, kemudian pergi merantau ke daerah tertentu. Kelompok yang disebut terakhir tidak mengalami persoalan serius dalam mengenali kearifan lokal di Sulit Air. Akan tetapi, kelompok yang pertama, cukup sulit memahaminya, terlebih jika kedua orang tuanya tidak memberikan pembinaan sejak dini. Akan tetapi, tidak sedikit mereka yang lahir dan besar di rantau atau bahkan sama sekali tidak bisa berbahasa Sulit Air, justeru memiliki kecintaan yang lebih kuat terhadap Sulit Air. Zulherfin Zubir adalah contohnya. Kepada penulis, Zulherfin bercerita bahwa dia pernah berada dalam kondisi sangat membenci apapun yang berbau "Sulit Air". Akan tetapi, setelah bergabung dalam Perkumpulan SAS dan menjadi Ketua Umum DPP SAS selama 12 tahun atau 6 periode, justeru Zulherfin menjadi sangat mencintai Sulit Air.

Semangat melakukan perubahan juga dilakukan oleh Dewan Pimpinan Cabang (DPC) SAS. Di Leverton, Melbourne, perantau Sulit Air melakukan terobosan dengan membeli sebuah geraja yang kemudian dialih-fungsikan sebagai rumah ibadah dan tempat pertemuan warga Sulit Air. Langkah ini juga dimaksudkan sebagai 
jalan dakwah sebagai kaum minoritas di Melbourne. Aktifitas filantropis ini menjadi viral di media sosial, sehingga semakin meningkatkan pengaruh SAS sebagai perkumpulan perantau yang memiliki kekuatan filantropi yang sangat besar. Berkaitan dengan kontribusi untuk nagari Sulit Air, setiap bulan DPC SAS Melbourne mengirimkan bantuan untuk pelaksanaan program tahfiz quran yang diselenggarakan oleh Majelis Ulama Nagari Sulit Air.

DPC SAS Padang termasuk cabang yang saat ini banyak melakukan inovasi program pemberdayaan warga Sulit Air di Padang. Misalnya, menjadikan gedung serba guna SAS sebagai pusat pendidikan keterampilan, sehingga seluruh warga, khususnya generasi muda yang tergabung dalam Ikatan Pemuda Pelajar Sulit Air dapat mengasah keterampilan-keterampilan tertentu. Hal yang sama juga dilakukan oleh DPC SAS Palembang yang secara berkesinambungan mengadakan pelatihan design grapich, dan lain sebagainya.

Program strategis lain yang dilakukan oleh DPC SAS Padang adalah melakukan konversi sistem koperasi yang telah memiliki asset di atas 1 milyar. Yaitu, dari sistem koperasi konvensional menjadi Koperasi Jasa Keuangan Syariah (KJKS). Upaya membangun koperasi juga dilakukan oleh DPC SAS Duri, di Riau. Melalui rapat warga, DPC SAS Duri telah membentuk koperasi yang diharapkan menjadi sarana untuk meningkatkan taraf perekonomian masyarakat Sulit Air di Duri.

\section{Kesimpulan}

Aktifitas filantropi kaum perantau Sulit Air Sepakat merupakan bentuk internalisasi nilai-nilai kearifan lokal masyarakat Minangkabau yang telah terkristalisasi dalam pandangan hidup adat bersendi syara', syara' bersendi kitabullah. Aktifitas ini telah dilakukan jauh sebelum kemerdekaan Indonesia dan terus melakukan adaptasi terhadap perkembangan zaman. Akan tetapi, tata kelola modal sosial ini masih bersifat tradisional, sehingga efektifitas dan efisensi dari program filantropi yang dilakukan, cenderung tidak berkesinambungan. Masalah ini diatasi dengan 
merekonseptualisasi program-program strategis dengan memanfaatkan perkembangan teknologi informasi, seperti: membangun sistem informasi SAS, program SAS peduli, beasiswa terpadu, pendirian lazis-SAS. 


\section{Referensi}

Abdullah, T. (1966). Adat and Islam: An examination of conflict in Minangkabau.

Abdullah, T. (1972). Modernization in the Minangkabau world: West Sumatra in the early decades of the twentieth century. Culture and politics in Indonesia, 179-243.

Addiarrahman. (2013). Baragiah Ka Kampuang: Spirit Filantropis Perantau Sulit Air. TURAST; JURNAL PENELITIAN DAN PENGABDIAN, 1(1), 67-80.

Adinegoro. (1963). Pembangunan Desa. Jakarta: Badan Penerbit JAPSA.

Baidhawy, Z. (2015). Lazismu and Remaking the Muhammadiyah's New Way of Philanthropy. Al-Jami'ah: Journal of Islamic Studies, 53(2), 387-412. https://doi.org/10.14421/ ajis.2015.532.387-412

Cizakca, M. (1998). Awqaf in history and its implications for modern Islamic economies.

David, W., \& Ploeger, A. (2014). Indigenous Knowledge (IK) of Water Resources Management in West Sumatra, Indonesia. Future of Food: Journal on Food, Agriculture and Society, 2(1), 52-60.

D'Kincai, R. (2003). Rainal Rais: abdi organisasi. Rora Karya.

Graves, E. E. (2007). Asal-usul elite Minangkabau modern: respons terhadap kolonial Belanda abad XIX/XX. Yayasan Obor Indonesia.

Huri, I. (2006). Filantropi kaum perantau: studi kasus kedermawanan sosial organisasi perantau Sulit Air Sepakat (SAS), Kabupaten Solok, Sumatera Barat. Piramedia.

Kato, T. (1980). Rantau Pariaman: The world of Minangkabau coastal merchants in the nineteenth century. The Journal of Asian Studies, 39(4), 729-752. 
Kisah Sulit Air dan Orang orang Kaya. (2016). Diambil 6 Juli 2019, dari detikx website: https://x.detik.com/detail/ intermeso/20160613/Kisah-Sulit-Air-dan-Orang-orang-Kaya/

Kuntowijoyo. (1991). Paradigma Islam Interpretasi untuk Aksi. Bandung: Mizan.

Latief, H. (2010). Melayani umat: filantropi Islam dan ideologi kesejabteraan kaum modernis. PT Gramedia Pustaka Utama.

Latief, H. (2013). Islamic philanthropy and the private sector in Indonesia. Indonesian Journal of Islam and Muslim Societies, 3(2), 175-201.

Maarif, A. S. (2009). Titik-titik kisar di perjalananku: autobiografi Abmad Syafii Maarif. PT Mizan Publika.

MacDonald, C. (2012). Understanding participatory action research: A qualitative research methodology option. The Canadian Journal of Action Research, 13(2), 34-50.

McCutcheon, R. T. (1999). The insider/outsider problem in the study of religion: A reader. A\&C Black.

Mohd Arshad, M. N. (2016). Determinants of charitable giving in Malaysia. Humanomics, 32(4), 459-473. https://doi. org/10.1108/H-01-2016-0007

Navis, A. A. (1984). Alam terkembang jadi guru: Adat dan kebudayaan Minangkabau. Grafiti Pers.

Noer, D. (1985). Gerakan Modern Islam di Indonesia 1900-1942. Jakarta: LP3ES.

Patriadi, H. B., Bakar, M. Z. A., \& Hamat, Z. (2015). Human Security in Local Wisdom Perspective: Pesantren and its Responsibility to Protect People. Procedia Environmental Sciences, 28, 100-105. https://doi.org/10.1016/j.proenv.2015.07.015

Rahardjo, D. (2015). Kemiskinan Pemikiran Dalam Kajian Islam Di Indonesia Menuju Ilmu-ilmu Sosial Profetik. Jurnal Sosiologi Reflektif, 10(1).

Rahardjo, M. D. (2012). Pembangunan pascamodernis: esai-esai ekonomi politik. Insist Press. 
Rankin, K. N. (2002). Social capital, microfinance, and the politics of development. Feminist economics, 8(1), 1-24.

Rusdiana, D., \& Saidi, Z. (2008). Diaspora giving: An agent of change in Asia Pacific communities. ht-tp://asianphianthrpy. rg/APPC/DiaspraGiving-cnference-2/DiaspraGivingIndnesia-28. pdfpp, 161-162.

Soebagio I.N. (1985). Riwayat Hidup dan Perjuangan H. Zainal Abidin Abmad. Jakarta: Pustaka Antara.

Vitasurya, V. R. (2016). Local Wisdom for Sustainable Development of Rural Tourism, Case on Kalibiru and Lopati Village, Province of Daerah Istimewa Yogyakarta. Procedia Social and Behavioral Sciences, 216, 97-108. https://doi. org/10.1016/j.sbspro.2015.12.014

Zainal Abidin Ahmad, dkk. (1978). Peringatan Setengah Abad PSA 1925-1978. PSA Sulit Air. 